\title{
School drop-out and push-out factors in Brazil: The role of early parenthood, child labor, and poverty
}

\author{
Ana Rute Cardoso* \\ IZA Bonn and University of Minho \\ and \\ Dorte Verner \\ World Bank, Latin American and the Caribbean Region
}

\begin{abstract}
This paper aims at identifying the major drop-out and push-out factors that lead to school abandonment in an urban surrounding, the shantytowns of Fortaleza, Northeast Brazil. We use an extensive survey addressing risk factors faced by the population in these neighborhoods, which covered both in-school and out-of-school youth, of both genders. The role of early parenthood, child labor, and poverty in pushing teenagers out of school is subject to particular attention. The potential endogeneity of some of determinants is dealt with in the empirical analysis. We take advantage of the rich set of variables available and apply an instrumental variables approach. Early parenthood is instrumented with the age declared by the youngsters as the ideal age to start having sexual relationships; work is instrumented using the declared reservation wage (minimum salary acceptable to work). Results indicate that early parenthood has a strong impact driving teenagers out of school. Extreme poverty is another factor lowering school attendance, as children who have suffered hunger at some point in their lives are less likely to attend school. In this particular urban context, working does not necessarily have a detrimental effect on school attendance, which could be linked to the fact that dropping out of school leads most often to inactivity, and not to work.
\end{abstract}

Keywords: school drop-out; investment in human capital; education; development. JEL codes: I21, O15, D1.

\section{World Bank Policy Research Working Paper 4178, March 2007}

The Policy Research Working Paper Series disseminates the findings of work in progress to encourage the exchange of ideas about development issues. An objective of the series is to get the findings out quickly, even if the presentations are less than fully polished. The papers carry the names of the authors and should be cited accordingly. The findings, interpretations, and conclusions expressed in this paper are entirely those of the authors. They do not necessarily represent the view of the World Bank, its Executive Directors, or the countries they represent. Policy Research Working Papers are available online at http://econ.worldbank.org.

\footnotetext{
* Corresponding author: Ana Rute Cardoso, IZA, Schaumburg-Lippe-Str. 7/9, 53113 Bonn, Germany. Email: cardoso@iza.org
} 


\section{Introduction}

Even though Brazil has reached almost universal enrollment in primary education, grade repetition and school drop-out and push-out are common. As a result, completion rates are substantially lower than enrollment, and many children abandon school with relatively low levels of completed education. The problem is particularly acute in poorer neighborhoods. Lower chances of finding a good job and poverty are some of the consequences of low educational attainment. As illustrated by Perlman "in the late 1960s, parents in the favela [shantytown] would often tell their children that if they did not stay in school they would end up as garbage collectors. In July 2003, the city [Rio de Janeiro] opened a competition for 400 garbage collector jobs, and 12,000 people applied. A high school diploma was a prerequisite for application" (Perlman 2003: 13).

This paper aims at identifying the major drop-out and push-out factors that lead to school abandonment in neighborhoods in Fortaleza, Northeast Brazil. It relies on an extensive survey that specifically addressed possible risk factors faced by the population in these neighborhoods, in particular the youth. The major advantages of the survey are its wide coverage, of both inschool and out-of-school youth, of both genders, and the wide set of issues addressed, namely: socio-economic background; education; health and sexuality; social capital and violence; and employment and economic activity.

In this paper we are particularly interested in evaluating the role of early parenthood, child labor and poverty pushing children out of school. However, those variables are potentially endogenous, first, because there may be determinants of the schooling decision on which we have no information and are therefore omitted from the set of explanatory variables we consider, and second, because child labor and early motherhood may be determined simultaneously with school drop-out. We therefore estimate an economic model of school drop-out and push-out using an instrumental variables method, taking advantage of the rich set of variables in the dataset. From the question "What age do you think is the ideal age to start having sexual relationships?" we derive an identifying instrument for early motherhood, since the belief about this ideal age is likely to induce variation in the age at which parenthood first takes place, but it should have no additional direct impact on the probability of leaving school. Similarly, we use the question "What is the minimum monthly salary that you would accept to work?" to instrument the variable child and youth labor. Again, the reasoning is that the reservation wage is likely to be correlated 
with whether the child or youth works, affecting the outcome of interest, whether (s)he attends school, solely through this channel of the labor decision.

The paper is organized in seven sections. Section 2 presents an overview of the Brazilian primary education system. The previous literature on the causes of school drop-out is briefly reviewed in section 3. Sections 4 and 5 present the data and its preliminary exploration. Section 6 describes the method and presents the results, before the conclusion, in section 7.

\section{Legal setting in Brazil}

Primary education covers in Brazil grades 1 through 8 and it is compulsory for ages 7 to 14 years. It comprises four years of elementary education and another four of intermediate education. Enrollment rates are high, with almost 100 percent of children starting the first grade. The country is pointed out as having been very successful at raising enrollment rates, from 67 percent in 1970 to 96 percent in 1998 for the age group 7-14 years. Part of that trend reflected the decline in birth rates, from 6 percent a year during the 1960s to 2 percent a year in late 1990s (UNESCO, 2006).

However, the inefficiency in the country's schooling system is also often highlighted, since it presents lower rates of actual school attendance than enrollment, and very high rates of grade repetition. In 1997, 23 percent of the students in the primary education system were bound to repeat a grade at the end of the school year, and another 4 percent dropped out (UNESCO, 2006). As a result, the gap between age and grade is large, and high enrollment rates do not translate into high completion rates or into a high level of schooling by school leavers. This situation occurs despite improvements that have been taking place, as the share of children completing eight years of primary education increased, from below half in 1990 to 72 percent ten years later (Bruns et al, 2003: 52-54). The school day lasts approximately 4 hours and in many places there are three shifts in a day (morning, afternoon, and evening). The minimum legal age to work in Brazil is 16 years, following the ratification in 2001 of International Labor Convention 138 on minimum age for admission into employment. 


\section{Previous literature's take on why teenagers drop out of school}

The analysis of the determinants of school drop-out in developed countries has highlighted factors such as drug use, alcohol consumption, and parents' psychiatric disorders, controlling for possible confounding factors such as socio-economic status of the family, gender, race, and age of the child. ${ }^{1}$ For developing countries, most often the trade-off between school and child labor has been underlined, with fewer studies concentrating just on the determinants of school performance. $^{2}$

In terms of method, earlier studies modeled the probability that the child would work or, in alternative, attend school, estimating a logit model. ${ }^{3}$ Underlying this approach was, in some cases, the idea that school attendance and child labor are mutually exclusive activities - if the child is working, (s)he is not attending school and vice-versa. In other cases, work was included among the exogenous factors explaining school performance. Results suggested that poverty, as captured for example by the number of siblings or the work status of the father, is a determinant of child labor and of poor school performance.

Later studies acknowledged the possibility of combining work and school, in particular in countries where school lasts just half-day. One method followed was the estimation of a multinomial logit model involving four possible states: specialization in school; specialization in labor; combination of both activities; or inactivity. ${ }^{4}$ Other authors accounted for the interdependence of the two decisions by estimating bivariate probit models. This allows, not just for an easy direct comparison of the impact of each variable on the probability of working and of studying, but also for the quantification of the non-explainable correlation between the two decisions, associated with unobserved factors. ${ }^{5}$ Both of these methods assume that the decisions on school and work are taken simultaneously. In the same vein, Rosati and Rossi (2003) estimated a simultaneous model of school attendance and hours worked. Some of the results in this literature, though not completely consensual, are: older children and males are more prone to

\footnotetext{
${ }^{1}$ See for example Chatterji and DeSimone (2005), Roebuck et al (2004), and Farahati et al (2003).

${ }^{2}$ School performance is understood as an indicator of time spent in school or school outcome, such as: enrollment, attendance, truancy, drop-out, highest level attained, grade repetition, or test scores. The first set of literature includes Ravallion and Wodon (2000), Fitzsimons (2002), Beegle et al (2004), Bacolod and Ranjan (2005), Maitra and Ray (2002), Parikh and Sadoulet (2005), Ganglmair (2006), Duryea and Arends-Kuenning (2003), Duryea et al (2003), Emerson and Souza (2002), Gunnarsson et al (2006), Rosati and Rossi (2003), Canagarajah and Coulombe (1997), Psacharopoulos (1997), Jensen and Nielsen (1997), and Patrinos and Psacharopoulos (1997). The second set includes Bedi and Marshall (2002), Akhtar (1996), and Pal (2004).

${ }^{3}$ See for example Patrinos and Psacharopoulos (1997), Psacharopoulos (1997) or, controlling for household unobservable factors, Jensen and Nielsen (1997), World Bank (2001), World Bank (2002), World Bank (2003).

${ }^{4}$ See for example Bacolod and Ranjan (2005), who also estimated a bivariate probit model, and Maitra and Ray (2002), who also estimated an ordered probit model.

${ }^{5}$ See Ganglmair (2006), Emerson and Souza (2002a), Duryea et at (2003), Duryea and Arends-Kuenning (2003), Parikh and Sadoulet (2005), Canagarajah and Coulombe (1997), and Emerson and Sousa (2002).
} 
combine school and work; older siblings are less likely to attend school; lower ability children are more likely to drop-out of school, specializing in work or becoming idle; there is intergenerational persistence in child labor status; higher family socio-economic status increases the probability that the child will stay in school and decreases the probability that (s)he will work; on the other hand, poverty motivates specialization in just labor or inactivity; families that run a business are more likely to have their children working, though not necessarily abandoning school; negative shocks affecting the household, such as the father becoming unemployed, raise the probability that the child will leave school and enter the labor market; there is a negative unexplained correlation between attending school and working.

Fitzsimons (2002), though going back to the assumption that child labor is the reverse of school attendance, provides further exploration of the role of income shocks. Going beyond the idea that the current level of household income determines the probability that the child will abandon school to work, she tests whether also the riskiness of the household income stream ${ }^{6}$ matters. Indeed, child labor could be used by the family as an insurance mechanism against fluctuations in income, in countries where insurance markets are underdeveloped. Her results lend support to the hypothesis that child labor has an insurance role, protecting against earnings volatility at the aggregate (village) level, whereas idiosyncratic (household level) risk is handled without resorting to the use of child labor.

Pal (2004) explicitly took into account the sequential nature of schooling progression, to estimate a sequential probit model. She finds that the determinants of school success differ according to the school level, with parental education being very relevant for primary school performance. Bedi and Marshall (2002) concentrate on the interrelation between school attendance and school achievement, finding that children with a higher expected achievement are more likely to attend school.

Still more recently, the endogeneity of child labor in regressions explaining schooling outcomes has been recognized, leading to the estimation of instrumental variable models. Different variables that shift the probability that the child works, while not having a direct impact on schooling outcomes, have been used. Gunnarsson et al (2006) explored variation across countries in the entry and exit ages of compulsory school; Ravallion and Wodon (2000) explored variation across villages in the participation in a food-for-school program; Beegle et al (2004) used

\footnotetext{
${ }^{6}$ Measured as village-level and household-level shocks to past earnings.
} 
variation across regions in rice prices ${ }^{7}$ and natural disasters in Vietnam. Results indicate that child labor lowers school performance. However, Ravallion and Wood find that the schooling subsidy, while strongly raising school attendance, reduced child labor to a much lower extent, since school parallel to labor is feasible due to the short duration of daily class time. Orazem and Gunnarsson (2004) provide an overview of the literature on the impact of labor on school outcomes, and in particular a discussion of instruments.

Instrumental variables has also been the empirical approach followed by Chatterji and DeSimone (2005), who used alcohol consumption in the previous month as instrument in their study of the impact of alcohol consumption on high school drop-out; similarly, Roebuck et al (2004) used indicators of religiosity to study the impact of drug use on schooling outcomes. We will follow this methodological line to study the factors pushing children out of school.

\section{The neighborhoods under study and data collection procedures}

\subsection{Fortaleza, Northeast Brazil}

Headcount poverty in the Northeast is among the highest in Brazil. ${ }^{8}$ Moreover, the state of Ceará, in particular, has one of the lowest HDI (Human Development Indicator, developed by United Nations Development Program) among Brazil's 27 states, even though it is the state that has improved the most this indicator, from 0.593 in 1991 to 0.700 in 2000.

The capital of the state, Fortaleza, is the fifth largest city in Brazil, with 2.1 million inhabitants, adding up to 2.8 million people when the metropolitan area is included. It has 402 favelas, of which 82 were classified as risk areas by the Military Police. During 1991-2000, the municipality of Fortaleza improved its HDI slightly less than the state as a whole, from 0.717 to 0.786. However, it is important to note that large disparities are observed when disaggregating the HDI by neighborhood. The most developed neighborhood in Fortaleza has a HDI comparable to that of industrialized countries (0.916), while the least developed neighborhoods have a level of development comparable to that of countries in Sub-Saharan Africa (0.338).

The three neighborhoods included in the survey are among the poorest in Fortaleza and this study thus covers a relatively homogenous urban area, in terms for example of low provision of infrastructure and public services.

\footnotetext{
${ }^{7}$ Which reduces child labor.

${ }^{8}$ This section draws heavily on Verner and Alda (2004).
} 


\subsection{Data}

The data—World Bank Fortaleza Survey_were collected in three neighborhoods in Fortaleza: Autran Nunes, Edson Queiroz, and Pirambú in 2003. ${ }^{9}$ Each has a population of around 20,000 people and around 4,500 houses. Approximately 500 questionnaires were applied in each neighborhood and, as a result, the sample contains about every ninth household in each of the three neighborhoods.

Two sets of teams were involved in the data gathering process: the research team, composed of statisticians from the local university, psychologists, NGOs, Human Rights spokespersons, youth and other people living in the selected neighborhoods; the interview team, composed of one general coordinator, three neighborhood coordinators, and the interviewers, recruited in each of the neighborhoods. The Institute of Organized Research of Ceará ${ }^{10}$ (IPOC), a local NGO operating in the poor neighborhoods, led the interview process. Both the pilot and final interviews were carried out by youth from the neighborhoods. Some of the interviewers were part of the MH2OCE (Organized Hip-Hop Movement of Ceará ${ }^{11}$ ), an organization that works on violence prevention in poor neighborhoods in Fortaleza. MH2OCE works with local gangs and their members, an arrangement that facilitated the team's access to the most violent areas of the neighborhoods, as it could negotiate access to areas under the control of violent groups, especially rival gangs. The interviews were conducted June 19-29, 2003, by five interviewers in each of the three neighborhoods. Each interviewer completed around 10 questionnaires daily, under close supervision of the team coordinator.

The survey instrument covered five major areas: i) socio-economic background; ii) education; iii) health and sexuality; iv) social capital and violence; and v) employment and economic activity. More details on the data collection procedures can be found in Verner and Alda (2004).

\subsection{Sample selection}

Different age brackets have been chosen by different studies of school performance and school drop-out, with the lower bound ranging from 5 to 18 years old, and the upper one from 13 to 21 , in the literature surveyed. The choice invariably involves some degree of arbitrariness and is often constrained by data availability. In the current study, the analysis will focus on teenagers aged 12 to 18 years (the lower bound being dictated by data availability, since very few

\footnotetext{
9 See Verner and Alda (2004).

${ }^{10}$ Instituto de Pesquisa Organizada do Ceará.

${ }^{11}$ Movimento Hip-Hop Organizado do Ceará.
} 
youngsters below the age of 12 were interviewed). Descriptive statistics are presented in table 3 in appendix.

\section{What distinguishes teenagers who are in school from those out-of-school? Descriptive statistics}

School attendance is computed from a direct question in the inquiry: "Do you attend or have attended school?" with the answer "yes, I currently attend" coded as our variable of interest. Figure 1 plots school attendance, by age and gender. Overall, a larger share of girls than boys remains in school. At age 12, school attendance is almost universal, but whereas for girls it remains at high values until age 17, for boys it drops to around 80 percent as early as age 13. Age 17 witnesses another sharp drop in school attendance for boys, down to about 60 percent and decreasing to 50 percent at age 18 . For girls, age 18 is the turning point, when the share attending school declines sharply, from 84 percent to 55 percent.

The fact that boys drop out of school more than girls contrasts with several other countries (see for example Jensen and Nielsen (1997) on Zambia, Maitra and Ray (2002) on Pakistan and Ghana). That pattern does however conform to evidence found for other Latin American countries (see for example Maitra and Ray (2002) on Peru).

The school level of those who abandoned school is rather low. The majority (three-fourths) dropped out before completing elementary school. Only 9 percent completed elementary school and 13 percent completed middle school.

Two different questions concentrate on the respondent's labor force status. The first one, "What do you do when you are not in school?" was coded as the teenager currently working if the answer was "I work". The second one is "Did you work in the past 12 months?" and its coding is obvious. 

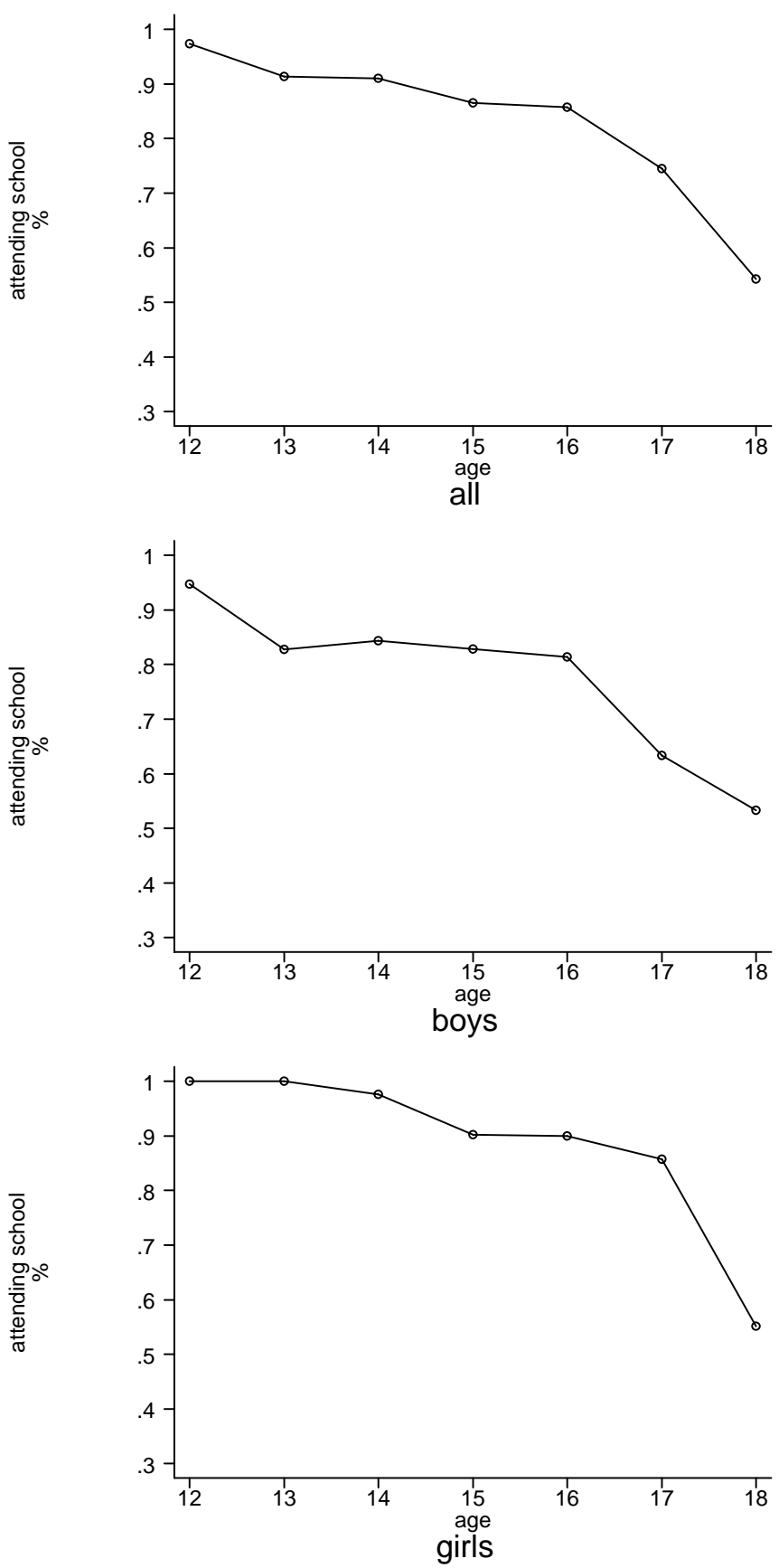

Figure 1 - School attendance, by age and gender.

Source: Own calculations based on World Bank, Fortaleza Survey 2003. 

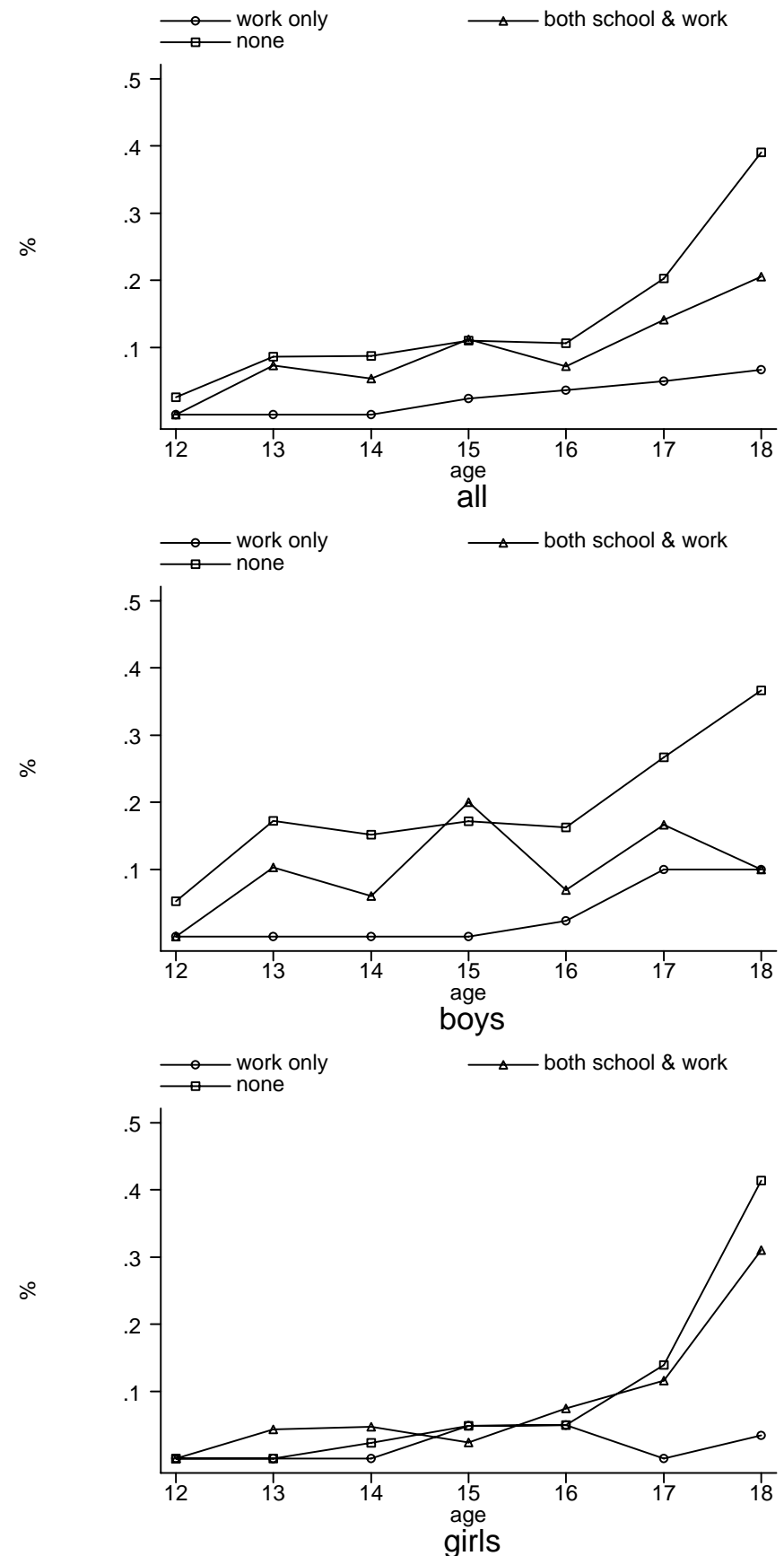

Figure 2 - Distribution of children according to school attendance and current work status, by age and gender.

Source: Own calculations based on World Bank, Fortaleza Survey 2003.

Note: There is one other category — attending school only-which is not plotted.

Figure 2 highlights that, after the age of 16, there is an increasing share of teenagers who, though not having a job, drop out of school. By the age of 18 , almost half of the teenagers is neither in school nor at work. These figures cast some doubt on the relevance of child labor as the driving force pulling teenagers out of school in urban Brazil. 


\begin{tabular}{|c|c|c|c|c|}
\hline \multirow[b]{3}{*}{ School/Work Status: } & \multicolumn{2}{|c|}{ In School } & \multicolumn{2}{|c|}{ Out of School } \\
\hline & Mean or Pct. & Std. Dev. & Mean or Pct. & Std. Dev. \\
\hline & 088 & & & \\
\hline both school and work & 0.12 & & & \\
\hline work only & & & 0.15 & \\
\hline neither work nor school & & & 0.85 & \\
\hline Worked past 12 months & 0.27 & & 0.47 & \\
\hline Girl & 0.54 & & 0.36 & \\
\hline Age & 15.11 & 1.71 & 16.38 & 1.65 \\
\hline Race: non-white & 0.56 & & 0.56 & \\
\hline Suffered hunger & 0.17 & & 0.36 & \\
\hline Dependent children $(\mathrm{y} / \mathrm{n})$ & 0.04 & & 0.30 & \\
\hline Ideal age first sex & 17.89 & 3.28 & 17.29 & 2.55 \\
\hline Ideal age first sex $<=17$ years old & 0.38 & & 0.45 & \\
\hline Monthly reservation wage (BRL) & 215.72 & 118.39 & 253.25 & 129.35 \\
\hline Father's schooling $>=$ interm. compl. & 0.06 & & 0.08 & \\
\hline Father's schooling $>=$ interm. compl. & 0.06 & & 0.09 & \\
\hline Schooling teenager: & & & & \\
\hline elementary inc. & 0.68 & & 0.73 & \\
\hline elementary compl. & 0.09 & & 0.09 & \\
\hline intermediate inc. & 0.21 & & 0.05 & \\
\hline intermediate compl. & 0.02 & & 0.13 & \\
\hline $\mathrm{N}$ & 36 & & 78 & \\
\hline
\end{tabular}

Table 1 - Comparison of teenagers in school and those out of school.

Source: Own calculations based on World Bank, Fortaleza Survey 2003

The issue is therefore: What distinguishes teenagers who are in school from those who have dropped out? Table 1 reports the comparison. As suggested by the previous graphs, girls are less represented among those out of school; older teens are more likely to have dropped out. In terms of race, no differences are apparent. Two remarkable differences stand out. Over one-third of the youngsters out of school declare to have suffered hunger at some point in their lives, compared to 17 percent for those in school. Also, almost one-third of those out of school have had children themselves, which compares to 4 percent for the teenagers attending school. When asked which age they considered as the ideal one to first have sexual relationships, almost half the teenagers out of school declared an age below or at 17 years old; 38 percent of those in school shared that benchmark. Even though the share of teenagers currently working is not very different across the groups in- and out-of-school, a larger share of those out of school has worked at some point during the past year. 


\section{Factors pushing teenagers out of school}

Descriptive evidence suggests that extreme poverty, early parenthood, and child labor may be factors pulling teenagers out of school. Nevertheless, a multivariate framework of analysis may uncover other relevant variables associated with school drop out and eventually bring into question the relevance of the ones previously highlighted. Moreover, a set of potentially confounding factors should be included as controls in the empirical analysis.

A major issue to be tackled is the potential endogeneity of the work decision and the early parenthood. Those who drop out of school are not a random sample and therefore a simple comparison of the schooling decisions of teens working and those not working, or those who are parents and those who are not, are likely to yield biased results. In particular, there may be omitted factors we cannot capture that affect the decision to abandon school, but are also determinants of early parenthood and of work status. Among such factors one might include the child's ability, motivation, and in general his/her preferences. We therefore adopt an instrumental variables approach.

We consider first of all the age indicated by the teenager as the ideal age to first have sexual relationships as an instrument for early motherhood. The underlying idea is that the belief about the right age to start having sex is likely to induce variation in the age at which motherhood or fatherhood first takes place, but it should have no additional direct impact on the probability of leaving school.

Similarly, the reservation wage - minimum amount of money the individual accepts to be

willing to start working - will be correlated with whether (s)he works or not, but it should not affect through any other channel the decision to abandon school. Analysis of the declared reservation wage suggests that teenagers indeed have an accurate idea of the market wage, thus supporting the claim that it can be used as an indicator of foregone earnings or the opportunity cost of the time in school. Figure 3 plots the reservation wage declared by the teenagers surveyed, revealing a very clear peak at the national minimum wage. We take the reservation wage as the identifying instrument for working in the labor market. 


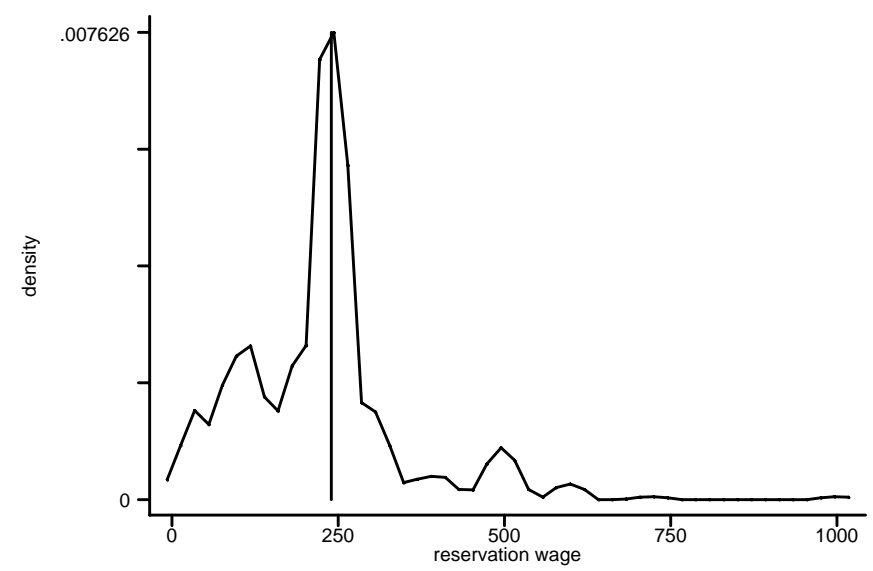

Figure 3 - Reservation wage.

Source: Own calculations based on World Bank, Fortaleza Survey 2003.

Note: the vertical line indicates the national minimum wage.

Stated more formally, we model the probability that the teenager will be out of school:

$$
\begin{aligned}
& \text { outschool }_{1 i}^{*}=Y_{2 i} \beta+X_{1 i} \gamma+u_{i} \\
& Y_{2 i}=X_{1 i} \pi_{1}+X_{2 i} \pi_{2}+v_{i}
\end{aligned}
$$

where $Y_{2 i}$ is a vector of endogenous variables — work and early parenthood-, $X_{1 i}$ is a vector of exogenous variables, which includes gender, age, race, having suffered hunger at some point in life, and mother's schooling level. $X_{2 i}$ includes our set of identifying instruments, the declared ideal age for first having sexual relationships (coded as one if that age is below or at 17 years old) and the reservation wage. We observe the child actually out of school if

$$
\text { outschool }_{1 i}=\left\{\begin{array}{lll}
0 & \text { if } & \text { outschool } \\
1 & \text { if } & \text { outschool } \\
1 i & \geq 0
\end{array}\right.
$$

Table 2 reports results of the estimation of the instrumental variables probit model. Column 1 includes a restricted set of control variables and column 2 reports a wider set. Results indicate, first of all, that the presence of own children drives youngsters away from school. Early parenthood increases by 0.46 the probability that the teenager will drop out of school (that is, the propensity to be out of school is 46 percentage points higher than for those who do not have children). Similarly, extreme poverty detracts from school attendance. Teenagers who declare they have suffered hunger are more prone to be out of school, with the probability increasing in this case by 0.11 . 


\begin{tabular}{|c|c|c|c|}
\hline \multirow{3}{*}{ Early parenthood } & Coef. & Coef. & Marg. impact \\
\hline & $1.053 * * *$ & $1.253 * * *$ & $.463 * * *$ \\
\hline & $(.333)$ & $(.277)$ & $(.096)$ \\
\hline \multirow[t]{2}{*}{ Work } & $-1.660 * * *$ & $-1.624 * * *$ & $-.399 * * *$ \\
\hline & $(.160)$ & $(.166)$ & $(.054)$ \\
\hline \multirow{2}{*}{ Female } & -.128 & -.109 & -.033 \\
\hline & $(.132)$ & $(.132)$ & $(.039)$ \\
\hline \multirow[t]{2}{*}{ Age } & $.216 * * *$ & $.206 * * *$ & $.065 * * *$ \\
\hline & $(.043)$ & $(.042)$ & $(.014)$ \\
\hline \multirow{6}{*}{ Schooling mother ( $>=$ interm. complete) } & $.338 * *$ & $.305 * *$ & $.105 * *$ \\
\hline & $(.152)$ & $(.150)$ & $(.054)$ \\
\hline & & .078 & .025 \\
\hline & & $(.126)$ & $(.041)$ \\
\hline & & -.039 & -0.012 \\
\hline & & $(.261)$ & $(.080)$ \\
\hline Cons & $-3.496 * * *$ & $-3.424 * * *$ & \\
\hline Log likelihood & -405.56 & \multicolumn{2}{|c|}{-403.35} \\
\hline Wald test on joint signif. coefs. & $\chi_{(5)}^{2}=245.76$ & \multicolumn{2}{|c|}{$\chi_{(7)}^{2}=247.49$} \\
\hline Number of obs. & 399 & \multicolumn{2}{|c|}{397} \\
\hline Wald test of exogeneity & $\chi_{(2)}^{2}=278.20$ & \multicolumn{2}{|c|}{$\chi_{(2)}^{2}=300.32$} \\
\hline
\end{tabular}

Table 2 - Probability of being out of school, instrumental variable probit model.

Note: Early parenthood and work are modeled as endogenous variables. Instruments include the declared ideal age for first having sexual relationships (coded as one if that age is below or at 17 years old) and the reference wage (see the text for further details). Level of significance: *** 1 percent; $* * 5$ percent; * 10 percent; standard errors in parenthesis. The reference to compute the marginal impacts is a male, with the mean age, white, whose mother did not complete intermediate schooling, who has not suffered hunger and declared a reservation wage equal to the national minimum wage. Impacts change little once alternative reference points are considered. For the dummy variables, the impact of a discrete change from 0 to 1 is reported.

Source: Own calculations based on World Bank, Fortaleza Survey 2003.

As opposed to most of the previous literature, we find that, in this particular urban context, having worked at some point during the past year does not have a detrimental effect on school attendance. As suggested when looking at raw figures, dropping out of school leads most often to inactivity, and not to work. This could be a result of the acute lack of employment opportunities currently faced by inhabitants of these neighborhoods. It could as well be that working for some hours allows funding for schooling. In fact, the field work suggests that not having as little money as that required to take the daily bus to go to school can lead to school drop-out.

Age has, as expected, a significant impact on school abandonment, with older teenagers more likely to give up school. After controlling for the above factors and the endogeneity of parenthood and work status, differences in drop-out rates between females and males are no longer significant. Similarly, the likelihood of being out of school does not differ significantly across race groups. This evidence is consistent with the reports by Perlman (2004: 128) who, 
having shown that the shantytowns (in her case in Rio) are racially quite mixed, found little correlation between race and several outcomes under scrutiny in her study: schooling, occupational status, political attitudes, social mobility, or perceptions of prejudice.

The schooling level of the mother, included in the specification as an indicator of the household economic position and of its preferences, does not have a significant impact on the probability that the teenager will drop out of school.

Although we are interested in the results form the second stage regression, it can be noted that the first stage parenthood regression has a relatively good predictive power (pseudo $R^{2} \mathrm{R}=0.20$ ). The first stage regression for the work status accounts for 9 percent of the exogenous variation in that variable.

We tested the assumption that working and early parenthood are endogenous to the schooling decision. The Wald test statistic points to the rejection of the null hypothesis of exogeneity of the instrumented variables, and therefore estimation of the instrumental variable model is more appropriate than a simple probit.

\section{Conclusion}

While most literature on developing countries has focused on the trade-off between school attendance and child labor, evidence from urban Brazil suggests other relevant forces may drive teenagers out of school, in particular early parenthood and extreme poverty. Empirical modeling of the impact of these variables is rendered difficult given their potential endogeneity. In the current study, the problem was circumvented by using the age declared by the teenager as the ideal one to have first sexual relationships as an instrument for early parenthood, and the declared reservation wage as an instrument for working in the labor market.

Findings indicate that early parenthood has a strong impact driving teenagers out of school. Extreme poverty is another factor lowering school attendance, as children who have suffered hunger at some point in their lives are less likely to be found attending school. In this particular urban context, working does not necessarily have a detrimental effect on school attendance. Dropping out of school leads most often to inactivity, and not to work, which could be due to the lack of employment opportunities. Another possible reasoning points to the role that working for some hours can have helping fund schooling. Indeed, costs such as daily transportation are often pointed out in interviews as obstacle to progress beyond a certain point in school. 
Some policy implications follow from these results. Reducing the costs of school (both direct and indirect), such as transportation, could improve the record of school attendance. One option would be to expand the conditional cash transfer program (Bolsa Familia) to youth aged 15-18 in poor neighborhoods. Moreover, early childhood development programs and improved nutrition and health would support development of cognitive skills of children in extreme poverty and would therefore have enduring implications on schooling outcomes. 


\section{References}

Akhtar, Sajjad (1996) Do girls have a higher school drop-out rate than boys? A hazard rate analysis of evidence from a Third World city. Urban Studies, 33(1): 49-62.

Bacolod, Marigee P. and Priya Ranjan (2005) Why children work, attend school, or stay idle: the roles of ability and household wealth. Mimeo, University of California-Irvine.

Bedi, Arjun S. And Jeffery H. Marshall (2002) Primary school attendance in Honduras. Journal of Development Economics, 69: 129-153.

Beegle, Kathleen, Rakeev Dehejia, and Roberta Gatti (2004) Why should we care about child labor? The education, labor market, and health consequences of child labor. NBER working paper 10980. Cambridge, MA: National Bureau of Economic Research.

Bruns, Barbara, Alain Mingat, and Ramahatra Rakotomalala (2003) Achieving Universal Primary Education by 2015: A Chance for Every Child. Washington DC: World Bank.

Canagarajah, Sudharshan and Harold Coulombe (1997) Child labor and schooling in Ghana. Policy Research working paper 1844. Washington DC: World Bank.

Chatterji, Pinka and Jeff DeSimone (2005) Adolescent drinking and high school dropout. NBER working paper 11337. Cambridge, MA: National Bureau of Economic Research.

Duryea, Suzanne and Mary Arends-Kuenning (2003) School attendance, child labor and local labor market fluctuations in urban Brazil. World Development, 31(7): 1165-1178.

Duryea, Suzanne, David Lam, and Deborah Levison (2003) Effects of economic shocks on children's employment and schooling in Brazil. PSC report 03-541. Michigan: Population Studies Center, University of Michigan.

Emerson, Patrick M. and André Portela Souza (2002) Birth order, child labor and school attendance in Brazil. Department of Economics working paper 02-W12. Nashville, TN: Vanderbilt University.

Emerson, Patrick M. and André Portela Souza (2002a) Bargaining over sons and daughters: child labor, school attendance and intra-household gender bias in Brazil. Department of Economics working paper 02-W13. Nashville, TN: Vanderbilt University.

Farahati, F., D. E. Marcotte, and V. Wilcox-Gok (2003) The effects of parents' psychiatric disorders on children's high school dropout. Economics of Education Review, 22: 167178.

Fitzsimons, Emla (2002) Risk, education and child labour in Indonesia. Mimeo, Institute for Fiscal Studies, London.

Ganglmair, Bernhard (2006) 'Intrinsic competition' and the labor-schooling trade-off in Uganda. Mimeo, University of Bonn.

Gunnarsson, Victoria, Peter F. Orazem, and Mario A. Sánchez (2006) Child labor and school achievement in Latin America. World Bank Economic Review, 20(1): 31-54.

Jensen, Peter and Helena Skyt Nielsen (1997) Child labour or school attendance? Evidence from Zambia. Journal of Population Economics, 10: 407-424. 
Maitra, Pushkar and Ranjan Ray (2002) The joint estimation of child participation in schooling and employment: comparative evidence from three continents. Oxford Development Studies, 30(1): 41-62.

Orazem, Peter and L. Victoria Gunnarsson (2004) Child labour, school attendance and performance: a review. Iowa State University working paper 04001.

Pal, Sarmistha (2004) Child schooling in Peru: further evidence from a sequential analysis of school progression. Journal of Population Economics, 17(4): 657-680.

Parikh, Anokhi and Elisabeth Sadoulet (2005) The effect of parents' occupation on child labor and school attendance in Brazil. Department of Agricultural and Resource Economics working paper 1000. California: University of California Berkeley.

Patrinos, Harry Anthony and George Psacharopoulos (1997) Family size, schooling and child labor in Peru - an empirical analysis. Journal of Population Economics, 10: 387-405.

Perlman, Janice E. (2003) The chronic poor in Rio de Janeiro: what has changed in 30 years? Conference on Chronic Poverty, Manchester, England, April 7-9.

Perlman, Janice E. (2004) Marginality: from myth to reality in the favelas of Rio de Janeiro, 1969-2002. In Ananya Roy and Nezar Alsayyad (eds.) Urban Informality: Transnational Perspectives from the Middle East, Latin America, and South Asia. New York: Lexington, p. 105-146.

Psacharopoulos, George (1997) Child labor versus educational attainment: some evidence from Latin America. Journal of Population Economics, 10: 377-386.

Ravallion, Martin and Quentin Wodon (2000) Does child labour displace schooling? Evidence on behavioural responses to an enrollment subsidy. Economic Journal, 110(462): C158C175.

Roebuck, M. Christopher, Michael T. French, and Michael L. Dennis (2004) Adolescent marijuana use and school attendance. Economics of Education Review, 23: 133-141.

Rosati, Furio Camillo and Mariacristina Rossi (2003) Children's working hours and school enrollment: evidence from Pakistan and Nicaragua. World Bank Economic Review, 17(2): 283-295.

Verner, Dorte and Erik Alda (2004) Youth at risk, social exclusion and intergenerational poverty dynamics: a new survey instrument with application to Brazil. Policy Research working paper 3296. Washington DC: World Bank.

World Bank (2001) Eradicating child labor in Brazil. Washington DC: World Bank.

World Bank (2002) Assessment of the Bolsa Escola Programs. Washington DC: World Bank.

World Bank (2003) Next steps for education in four selected states in Brazil.Washington DC: World Bank.

Unesco (2006) Website http://www2.UNESCO.org/countryreports/brazil/contents.html (consulted August 7) 


\section{Appendix}

\begin{tabular}{|c|c|c|}
\hline \multirow[b]{2}{*}{ School/Work Status: } & Mean or Pct. & Std. Dev. \\
\hline & 0.72 & \\
\hline work only & 0.03 & \\
\hline neither school nor work & 0.15 & \\
\hline both school and work & 0.10 & \\
\hline Work currently & 0.13 & \\
\hline Worked past 12 months & 0.31 & \\
\hline Girl & 0.51 & \\
\hline Age & 15.34 & 1.76 \\
\hline Race: non-white & 0.56 & \\
\hline Suffered hunger & 0.20 & \\
\hline Dependent children (y/n) & 0.08 & \\
\hline Ideal age first sex & 17.79 & 3.16 \\
\hline Ideal age first sex $<=17$ years old & 0.40 & \\
\hline Monthly reservation wage (BRL) & 225.24 & 135.26 \\
\hline Father's schooling $>=$ interm. compl. & 0.07 & \\
\hline Father's schooling $>=$ interm. compl. & 0.07 & \\
\hline $\begin{array}{l}\text { Schooling teenager: } \\
\text { elementary inc. }\end{array}$ & 0.69 & \\
\hline elementary compl. & 0.09 & \\
\hline intermediate inc. & 0.18 & \\
\hline intermediate compl. & 0.04 & \\
\hline $\mathrm{N}$ & & \\
\hline
\end{tabular}

Table 3 - Summary statistics, full sample of teenagers.

Source: Own calculations based on World Bank, Fortaleza Survey 2003. 